\title{
Estado actual de la Reforma Procesal en Chile
}

\author{
Juan Enrique Vargas*
}

El año 2005 marca un hito en el proceso de implementación de la reforma procesal penal chilena, tanto por cumplirse cinco años desde su inicio, como por haberse completado el proceso progresivo de puesta en marcha en todas las regiones del país, a partir del inicio del nuevo sistema en la Región Metropolitana el día 16 de junio. Más allá de haberse extendido en seis meses el calendario inicial de implementación, es un hecho a destacar que se haya cumplido en forma exitosa el proceso gradual de puesta en marcha de esta reforma trascendental. Ese proceso de implementación significó la creación de nuevas instituciones, como el Ministerio Público y la Defensoría Penal Pública; una modificación sustancial en la estructura y funcionamiento de los Tribunales (creándose los tribunales de garantía y los orales en lo penal, como grandes unidades jurisdiccionales gestionadas centralizadamente por administradores profesionales); la generación de instancias de coordinación entre estas mismas instituciones; un violento cambio en los procesos de trabajo de las policías y servicios periciales; y, en fin, todo lo anterior supuso la selección y contratación de una enorme cantidad de nuevos funcionarios y la inversión de cuantiosos recursos (más de 500 millones de dólares).

Pero más allá de los resultados positivos obtenidos en el proceso mismo de implementación, lo significativo es apreciar la forma cómo el nuevo sistema se está acercando a los objetivos que se propusieron al momento de su creación. Así, por ejemplo, existe una clara diferenciación en los roles de los distintos actores, sin existir interferencias serias entre ellos; la publicidad se ha asentado en todas las intervenciones jurisdiccionales, lo mismo que los principios de oralidad y contradicción; los derechos del imputado, particularmente los de presunción de inocencia y a la defensa, están siendo no sólo respetados, sino que activamente promovidos; se han desarrollado prácticas que mejoran la situación de la víctima frente al proceso penal; $y$, en general, el sistema es capaz de procesar adecuadamente la carga de trabajo que ingresa y de dar respuestas diferenciadas a la misma en tiempos razonables. También en términos generales es posible afirmar que se ve un compromiso fuerte y leal de las instituciones del sector con el éxito del nuevo sistema de justicia penal. Igualmente, las prácticas más viciosas del antiguo sistema, como los espacios de corrupción o de tráfico de influencias, aparecen claramente relegadas sino abolidas.

En términos cuantitativos, los resultados obtenidos con la reforma pueden sintetizarse en las siguientes cifras:
* Abogado y Magíster en Gestión y Políticas Públicas. Director Ejecutivo de CEJA.
Este comentario está disponible en: www.anuariocdh.uchile.cl 
1 La Unidad de Cuenta que hoy se utiliza en Chile es la de "relaciones" y no la de expediente o caso. Una relación se genera por cada delito imputado a un sujeto determinado. Es mucho más precisa que la de expediente, pues uno de ellos, como se sabe, puede abarcar infinidad de delitos e imputados.
- Desde su inicio en el año 2000 hasta el 30 de noviembre de 2004, ingresaron al Ministerio Público 1.124.470 relaciones ${ }^{1}$, de las cuales se encontraban terminadas 992.658 , lo que corresponde a un $88 \%$ del total. Si se consideran sólo los datos del año 2004, el porcentaje de término se eleva a un $90 \%$, el cual es superior al $89 \%$ que se fijó como meta del sistema al momento de ser diseñado.

- El nuevo sistema es capaz de generar respuestas en forma mucho más rápida que el antiguo. Los tiempos se redujeron, en promedio, en un $61 \%$ en comparación con el sistema antiguo. La gradualidad ha tenido una importante contribución en la reducción de las demoras: si en las regiones de la primera fase (año 2000) el tiempo promedio que tardaba un asunto desde que se judicializa hasta que se terminaba era en el primer año 198 días, en las regiones de la cuarta fase (año 2004) se redujo a 86 días.

- Si se analiza la forma en que terminan los asuntos, al año 2004 un $17 \%$ de ellos concluyó a través de las Ilamadas "soluciones de calidad", que son aquellas donde hay realmente una respuesta frente al delito y no un simple reconocimiento de fracaso del sistema (sentencias, acuerdos reparatorios, suspensiones y sobreseimientos definitivos). Esta cifra va en constante aumento y existen regiones en que es sustantivamente más alta que en el promedio (en la III Región alcanza el $37 \%$ del total).

- La percepción pública de la ciudadanía es muy favorable frente al nuevo sistema. Una encuesta realizada por IPSOS en el mes de diciembre de 2004 , indicó que entre un $78 \%$ y un $85 \%$ de los encuestados conoce o ha oído hablar de la reforma, dependiendo de la región; un $77,2 \%$ cree que la reforma ha agilizado casos; un $71,1 \%$ cree que la reforma ha hecho más transparente la justicia, y un 75,9\% prefiere la reforma al sistema antiguo (sólo un 14,1\% al antiguo).

Resulta determinante para explicar estos buenos resultados la especial preocupación habida por los temas de gestión. Si bien en términos comparativos en cada una de las instituciones del sector los avances en esta materia son significativos en relación a la situación prerreforma, no es posible desconocer que en esta materia aún quedan muchos desafíos por asumir y prácticas por afinar. Al respecto hay dos temas que resultan dignos de atención. Por un lado, la existencia de una amplia heterogeneidad de modelos de organización y funcionamiento entre las distintas unidades de esas instituciones, heterogeneidad que incluso es posible advertir entre ciudades vecinas de una misma región. Ello da cuenta de que el proceso de innovación ha sido sumamente ágil y desformalizado, descansando más bien en iniciativas de carácter local que en políticas generales, lo que resulta entendible y positivo en una fase inicial de implementación; pero que, a su vez, puede convertirse en un lastre en fases posteriores, si no hay un esfuerzo sistemático por relevar y masificar las prácticas más exitosas. Por otro lado, es claro que el sistema aún no se encuentra en régimen, es decir, no ha recibido el máximo de la carga de trabajo esperada para él. Sin embargo, la sensación general 
de los actores, expresada en numerosas oportunidades por los superiores institucionales, es que están saturados de trabajo con niveles de trabajo mayores a los que pueden soportar. Esa sensación no es avalada por las cifras del sistema y los estudios practicados, pareciendo más bien que se debe a defectos o insuficiencias en la gestión, que generan innumerables trámites o prácticas innecesarias, muchas de ellas formalistas y burocratizadas.

Son cuatro los factores que resultarán clave para consolidar, e incluso mejorar, los resultados exhibidos hasta la fecha, en todos los cuales es posible avanzar aún más de lo que se ha hecho hasta hoy:

1. Coordinación interinstitucional: Hasta el momento sólo ha funcionado una instancia formal de coordinación interinstitucional que agrupa a las máximas cabezas a nivel nacional del sector justicia. Sin embargo, ella sólo es efectiva para analizar los macroproblemas, pero no aquellos operativos que se producen cotidianamente en cada una de las localidades del país y que requieren de una solución negociada entre las instituciones como, por ejemplo, el horario y la forma de organización de las audiencias.

2. Evaluación y seguimiento: Una reforma de esta naturaleza y complejidad requiere de un constante proceso de evaluación y seguimiento que permita ir introduciendo los ajustes de gestión y normativos que sean necesarios. Hasta el momento estas evaluaciones han sido esporádicas y han carecido de indicadores claros previamente establecidos. Ellas, por lo demás, han descansado en información estadística que aún presenta importantes problemas de homologabilidad entre las instituciones.

3. Espacio de poder real para los administradores: Como se decía, tan relevante como el nuevo modelo jurídico de trabajo que introdujo el nuevo sistema, desjudicializando la investigación y oralizando todas las intervenciones jurisdiccionales, incluyendo las de la etapa de investigación en que las peticiones de las partes son resueltas en audiencia (de hecho en el Centro de Justicia de Santiago se opera sin papeles, quedando toda la información en registro digital), es la modificación del aparato administrativo y de gestión que ha permitido tales innovaciones. Pieza clave en esos cambios son los administradores profesionales (ingenieros y administradores públicos) que se han incorporado en todas las instituciones del sector. Sin embargo, no es fácil que ellos sean aceptados con un espacio de poder propio por parte de los operadores jurídicos (jueces, fiscales y defensores). No es tan resistido por éstos, por ejemplo, que los administradores asuman la gestión de los recursos materiales del tribunal, pero les es bastante más difícil aceptar que sea el administrador el que controle la agenda del tribunal, pese a que, sin duda, este es el recurso más crítico en su interior. El proceso de asimilación ciertamente será largo, pero requiere para su concreción de un muy fuerte liderazgo por parte de las autoridades del sector. 
4. Desformalización y desburocratización: Existe una permanente tentación en el mundo de lo judicial por establecer ritos y trámites sin una real justificación y sin apreciar los costos que ellos envuelven para el funcionamiento general del sistema. En la reforma procesal penal chilena se avanzó muchísimo en un inicio para desprenderse de la gran mayoría de ellos, generando una forma de funcionamiento sumamente ágil. Sin duda, ha sido una gran ayuda para ello la fuerza con que se incorporó la oralidad en todas las actuaciones judiciales, pues la sola dinámica de someter las cuestiones a un debate oral va dejando en el olvido las formas sin sentido. Sin embargo, atentan contra esa evolución la poca exposición que han tenido las Cortes hacia la reforma, lo que muchas veces las Ileva a no entender los cambios y a imponer regresiones hacia lo conocido. También atenta contra este proceso de innovación la falta de liderazgos sostenidos en el tiempo dentro de cada oficina de las instituciones del sector, que estén constantemente impulsando nuevas metodologías de trabajo.

Adicionalmente a estos temas que guardan relación con la lógica interna de la reforma, ella también debe seguir ganando espacios como política pública que es. Allí el principal problema se presenta por la tradicional tensión dentro de un sistema penal entre garantías y eficiencia. Hasta la fecha la reforma ha resuelto bien este tema demostrando que no hay un juego de suma cero entre ambas, pues al mismo tiempo que se ha elevado el estándar de las garantías, la cantidad de respuestas y su velocidad han crecido significativamente. Sin embargo, este es un tema de alta sensibilidad y volubilidad en la opinión pública; aspectos que en algún momento pueden ser bien evaluados, como la disminución en el uso de la prisión preventiva que implica el nuevo sistema, pueden convertirse rápidamente en un flanco de ataques, como efectivamente ha sucedido durante las campañas electorales.

La reforma, por lo demás, ha demostrado singular eficacia a la hora de investigar y resolver la criminalidad más compleja, pero ha tenido problemas con los delitos de menor significación, lo que en algún momento generó cierta imagen de impunidad, que problemas de coordinación interinstitucional y deficiencias legislativas se encargaron de exacerbar. Hoy en día en ambos frentes se ha avanzado con un mayor entendimiento y compromiso de las policías con los cambios y con reformas legales que han resuelto los vacíos y errores más evidentes al nivel normativo. Sin embargo, hay todavía espacios importantes donde se debe avanzar, principalmente para utilizar en forma más estratégica los enormes recursos con que cuenta el Ministerio Público, de forma tal que este no sea sólo un instrumento reactivo frente a los delitos cometidos, sino que pueda actuar proactivamente frente a los fenómenos delictuales, insertándose de forma adecuada en las políticas preventivas generales que debe impulsar el Estado. 